\title{
Tyrosinase Inhibitors from the Stems of Streblus Ilicifolius
}

\author{
Nhan T. Nguyen $\mathbb{D}^{1,2,3}$ Phu H. Dang $\mathbb{D}^{1,2}$ Hai X. Nguyen $\mathbb{D}^{1,2}$ Truong N. V. Do $\mathbb{D}^{1,2}$ \\ Tho H. Le $\mathbb{D}^{1,2}$ Tuyen Q. H. Le $\mathbb{D}^{1,2}$ and Mai T. T. Nguyen $\mathbb{D i D}^{1,2,3}$ \\ ${ }^{1}$ Faculty of Chemistry, University of Science, 227 Nguyen Van Cu Street, Ward 4, District 5, Ho Chi Minh City, Vietnam \\ ${ }^{2}$ Vietnam National University, Quarter 6, Linh Trung Ward, Thu Duc District, Ho Chi Minh City, Vietnam \\ ${ }^{3}$ Cancer Research Laboratory, University of Science, 227 Nguyen Van Cu Street, District 5, Ho Chi Minh City, Vietnam
}

Correspondence should be addressed to Mai T. T. Nguyen; nttmai@hcmus.edu.vn

Received 18 March 2021; Accepted 25 June 2021; Published 1 July 2021

Academic Editor: Hilal Zaid

Copyright (C) 2021 Nhan T. Nguyen et al. This is an open access article distributed under the Creative Commons Attribution License, which permits unrestricted use, distribution, and reproduction in any medium, provided the original work is properly cited.

\begin{abstract}
Two new stilbene derivatives, named strebluses C and D, were isolated from the EtOAc-soluble fraction of the stems of Streblus ilicifolius (Moraceae). Its absolute configuration was elucidated based on NMR spectroscopic data interpretation and optical rotation calculation. Streblus C possesses strong tyrosinase inhibitory activity with an $\mathrm{IC}_{50}$ value of $0.01 \mu \mathrm{M}$. Docking studies of 1 and $\mathbf{2}$ with $o x y$-tyrosinase were carried out to analyze their interactions. The analysis of the docked poses confirmed that $\mathbf{1}$ showed better binding affinity for $o x y$-tyrosinase than that of 2 .
\end{abstract}

\section{Introduction}

Tyrosinase (EC 1.14.18.1), which is a binuclear coppercontaining monooxygenase, is a key enzyme in the oxidation of phenol to the corresponding $o$-quinone $[1,2]$. It plays a main factor causing freckles, brown age spots, and melasma. Some commercial compounds, such as hydroquinone, arbutin, kojic acid, azelaic acid, L-ascorbic acid, ellagic acid, and tranexamic acid, were reported as the well-known tyrosinase inhibitors. These compounds have been used as skin whitening agents in cosmetic products, but they have certain drawbacks [3]. Thus, the finding of the new efficient and safe tyrosinase inhibitors is necessary for antihyperpigmentation product development.

Streblus ilicifolius (Vidal) Corner, which belongs to Moraceae family, was found and cultivated in Vietnam. Its barks have been traditionally used as an antipimple medicine. In a few published studies, some phenolic compounds have been reported in this plant [4-7]. In our continued studies on the screening of medicinal plants for tyrosinase inhibitory activity [8-12], it was found that a $\mathrm{MeOH}$-soluble extract of the stems of Streblus ilicifolius showed a strong inhibitory effect, with an $\mathrm{IC}_{50}$ value of $0.63 \mu \mathrm{g} \cdot \mathrm{mL}^{-1}$. Thus, our study on chemical constituents of the stems of S. ilicifolius was carried out, leading to the isolation of two undescribed stilbene derivatives, strebluses C (1) and D (2). Compound 1 showed a strong tyrosinase inhibitory activity with an $\mathrm{IC}_{50}$ value of $0.01 \mu \mathrm{M}$, which makes it 4400 times more potent than that of kojic acid $\left(\mathrm{IC}_{50}, 44.6 \mu \mathrm{M}\right)$. In addition, molecular docking studies of $\mathbf{1}$ and 2 with the $o x y$ form of the copper-bound Streptomyces castaneoglobisporus tyrosinase were performed.

\section{Materials and Methods}

2.1. General Experimental Procedures. Optical values were measured on a Shimadzu UV-1800 spectrophotometer (Shimadzu Pte., Ltd., Singapore). IR spectra were measured with a Shimadzu IR-408 infrared spectrometer (Shimadzu Pte., Ltd., Singapore). NMR spectra were acquired on a Bruker Avance III 500 spectrometer (Bruker BioSpin AG, Bangkok, Thailand). Chemical shifts are expressed as $\delta$ values. HRESIMS data were acquired on Bruker micrOTOFQII mass spectrometer (Bruker Singapore Pte., Ltd., Singapore). Column chromatography was carried out using silica gel 60, 0.06-0.2 mm (Scharlau, Barcelona, Spain), and 
LiChroprep RP-18, 40-63 $\mu \mathrm{m}$ (Merck KGaA, Darmstadt, Germany). Kieselgel $60 \mathrm{~F}_{254}$ or RP-18 $\mathrm{F}_{254}$ plates for TLC were purchased from Merck (Merck KGaA, Darmstadt, Germany). Tyrosinase (EC 1.14.18.1) from mushroom (3933 U.mL $\mathrm{mL}^{-1}$ ) and L-dihydroxyphenylalanine (L-DOPA) were obtained from Sigma-Aldrich (Sigma-Aldrich Pte Ltd, Singapore). Other chemicals were of the highest grade available.

2.2. Plant Material. The stems of Streblus ilicifolius were collected at Hoai Nhon District, Binh Dinh Province, Vietnam, in October 2017. The plant was identified by Dr. rer. nat. Anh Tuan Dang-Le, Faculty of Biology and Biotechnology, University of Science, Ho Chi Minh City, Vietnam. A voucher sample (MCE0052) has been deposited at the Department of Medicinal Chemistry, Faculty of Chemistry, University of Science, Ho Chi Minh City, Vietnam.

2.2.1. Extraction and Isolation. The dried powdered stems of S. ilicifolius $(7.0 \mathrm{~kg})$ were exhaustively extracted in a Soxhlet extractor with $n$-hexane, EtOAc, and $\mathrm{MeOH}$ to yield $n$ hexane-(64.8 g), EtOAc-(117.2 g), and $\mathrm{MeOH}-(378.0 \mathrm{~g})$ soluble fractions, respectively. The EtOAc-soluble fraction was chromatographed by silica gel column chromatography $(15 \times 150 \mathrm{~cm})$ and eluted with $\mathrm{MeOH}-\mathrm{CHCl}_{3}$ (v/v, 0 : $100 \longrightarrow 100: 0)$ mixtures to afford 18 fractions (Fr.1-Fr.18). Fraction Fr.8 (0.8 g) was separated by silica gel column chromatography with $\mathrm{MeOH}-\mathrm{CHCl}_{3}(\mathrm{v} / \mathrm{v}, 0: 100 \longrightarrow 30$ : 70) mixtures to obtain six subfractions (Fr.8.1-Fr.8.6). Subfraction Fr.8.1 (34.8 mg) was loaded onto a silica gel column and eluted with EtOAc- $\mathrm{CHCl}_{3}$ mixtures (v/v, 0 : $100 \longrightarrow 100: 0)$ and then purified by preparative TLC with an EtOAc- $\mathrm{CHCl}_{3}$ mixture (v/v, $\left.15: 85\right)$ to afford compound $2(2.0 \mathrm{mg})$. Fraction Fr.14 (19.6 g) was subjected to further silica gel column chromatography and was eluted with $\mathrm{CHCl}_{3}-n$-hexane $(\mathrm{v} / \mathrm{v}, 0: 100 \longrightarrow 100: 0)$ mixtures to yield 11 subfractions (Fr.14.1-Fr.14.11). Subfraction Fr.14.2 (69.0 mg) was chromatographed over a silica gel column with $\mathrm{CHCl}_{3}-n$-hexane (v/v, $\left.0: 100 \longrightarrow 100: 0\right)$ mixtures to obtain two subfractions (Fr.14.2.1 and Fr.14.2.2). Subfraction Fr.14.2.2 (28.1 mg) was again chromatographed with $\mathrm{CHCl}_{3}-n$-hexane $(\mathrm{v} / \mathrm{v}, 0: 100 \longrightarrow 100: 0)$ mixtures to give four subfractions (Fr.14.2.2.1-Fr.14.2.2.4). Subfraction Fr.14.2.2.3 (8.5 mg) was purified by preparative TLC with EtOAc-n-hexane (v/v, $20: 80)$ mixture to afford 1 (3.9 mg).

2.2.2. Streblus $C$ (1). Yellow, amorphous powder; ${ }^{1} \mathrm{H}$ and ${ }^{13} \mathrm{C}$ NMR $\left(500 \mathrm{MHz}\right.$, acetone- $d_{6}$, see Table 1 and Figures S2-S7); HRESIMS $m / z \quad 393.1704 \quad[\mathrm{M}+\mathrm{Na}]^{+}$ (Figure S8) (calcd for $\mathrm{C}_{22} \mathrm{H}_{26} \mathrm{O}_{5} \mathrm{Na}, 393.1678$ ).

2.2.3. Streblus D (2) (Figures S9-S15). Yellow, amorphous powder; ${ }^{1} \mathrm{H}$ and ${ }^{13} \mathrm{C} \mathrm{NMR}\left(500 \mathrm{MHz}\right.$, acetone- $d_{6}$, see Table 1 and Figures S8-S14); HRESIMS $m / z$ 351.1224 $[\mathrm{M}+\mathrm{Na}]^{+}$ (Figure S15) (calcd for $\mathrm{C}_{19} \mathrm{H}_{20} \mathrm{O}_{5} \mathrm{Na}, 351.1208$ ).
2.3. Tyrosinase Inhibitory Assay. All pure compounds were dissolved in DMSO and tested at concentrations ranging from 0.01 to $100 \mu \mathrm{M}$. Assay mixtures in $0.1 \mathrm{M}$ phosphate buffer $\mathrm{pH} 6.8$ were prepared immediately before use, consisting of $100 \mu \mathrm{L}$ of tyrosinase solution $(15 \mathrm{U} / \mathrm{mL})$ and $1900 \mu \mathrm{L}$ of test solution. These mixtures were preincubated at $32^{\circ} \mathrm{C}$ for $30 \mathrm{~min}$, followed by addition of $1000 \mu \mathrm{L}$ of $\mathrm{L}^{-}$ DOPA $1.5 \mathrm{mM}$ in pH 6.8 phosphate buffer, and incubated at $32^{\circ} \mathrm{C}$ for $7 \mathrm{~min}$. The absorbance $(A)$ at $475 \mathrm{~nm}$ was acquired on Shimadzu UV-1800 spectrophotometer. The inhibitory percentage $(I \%)$ was calculated according to the formula: $I$ $\%=\left[\left(A_{\text {control }}-A_{\text {sample }}\right) / A_{\text {control }}\right] \times 100 \%$. Data were represented as means \pm standard error $(n=3)$. The $\mathrm{IC}_{50}$ values were determined by using GraphPad Prism software with multivariate nonlinear regression and $R^{2}>0.9$. Kojic acid was used as positive control.

2.4. HPLC Data of the EtOAc-Soluble Fraction from S. ilicifolius. The concentrations of the EtOAc-soluble fraction and streblus C (1) were approximately 12,000 ppm and $200 \mathrm{ppm}$, respectively. The detection wavelength was set at $385 \mathrm{~nm}$. An Agilent Zorbax SB-C18 column $(150 \times 4.6 \times 5 \mathrm{~mm})$ was used with a flow rate of $1 \mathrm{~mL} / \mathrm{min}$. The injection volume was $10 \mathrm{Ml}$, and the column temperature was maintained at $30^{\circ} \mathrm{C}$. The mixtures of water and $\mathrm{ACN}$ were used as the mobile phase with gradient elution $(20 \longrightarrow 40 \% \mathrm{ACN}$ for $30 \mathrm{~min})$.

2.5. Optical Rotation Calculation. The conformational searches were performed on Spartan'18 (Wave function, Inc., Irvine, USA) by using Merck molecular force field (MMFF). All conformers with Boltzmann weight ' $10 \%$ were optimized using DFT method at the B3LYP/6-31G* level in the gas phase, to give the preferred conformers with the Boltzmann weight $>90 \%$. The optical rotation calculations at sodium D line frequency were carried out using the B3LYP functional and the $6-311++\mathrm{G}(2 \mathrm{~d}, 2 \mathrm{p})$ basis set in IEFPCM solvation model for methanol. These calculations were performed on Gaussian 09 (Gaussian, Inc., Wallingford, USA). The calculated optical rotation values were expressed as Boltzmann-weighted average of all output data.

2.6. Molecular Docking. Docking studies of $\mathbf{1}$ and 2, positive reference (kojic acid), and decoy (hypoxanthine) were performed with Molecular Operating Environment 2019 (MOE 2019.0102) suite (Chemical Computing Group ULC, Montreal, Canada). The structures of these compounds were constructed by using the Builder module. Subsequently, all compounds were minimized up to 0.0001 gradients using the Amber12: EHT force field. The crystal structure of the $o x y$-tyrosinase was taken from the Protein Data Bank (PDB ID : 1WX2). The caddie protein (ORF378) and water molecules were removed. The enzyme structure was prepared using the QuickPrep module. The binding site was determined based on the Propensity for Ligand Binding (PLB) score in the Site Finder module. The molecular docking was performed by Dock Module, using Triangle Matcher 
Table 1: ${ }^{1} \mathrm{H}(500 \mathrm{MHz})$ and ${ }^{13} \mathrm{C}(125 \mathrm{MHz})$ NMR data (acetone- $\left.d_{6}\right)$ for compounds 1 and 2.

\begin{tabular}{|c|c|c|c|c|}
\hline \multirow{2}{*}{ Position } & \multicolumn{2}{|c|}{1} & \multicolumn{2}{|c|}{2} \\
\hline & $\delta_{\mathrm{C}}$, type C & $\delta_{\mathrm{H}}(J, \mathrm{~Hz})$ & $\delta_{\mathrm{C}}$, type $\mathrm{C}$ & $\delta_{\mathrm{H}}(J, \mathrm{~Hz})$ \\
\hline 1 & $116.3, \mathrm{C}$ & & 122.0, C & \\
\hline 2 & $158.3, \mathrm{C}$ & & 158.0, C & \\
\hline 3 & 103.6, $\mathrm{CH}$ & $6.46, \mathrm{~d}(2.4)$ & 98.3, CH & $7.00, \mathrm{~d}(2.1)$ \\
\hline 4 & $160.8, \mathrm{C}$ & & $158.9, \mathrm{C}$ & \\
\hline 5 & $108.9, \mathrm{CH}$ & $6.42, \mathrm{dd}(8.5,2.4)$ & $114.3, \mathrm{CH}$ & $6.87, \mathrm{dd}(8.5,2.1)$ \\
\hline 6 & 129.6, CH & $7.48, \mathrm{~d}(8.5)$ & $123.4, \mathrm{CH}$ & $7.52, \mathrm{~d}(8.5)$ \\
\hline $1^{\prime}$ & $153.9, \mathrm{C}$ & & 143.6, C & \\
\hline $2^{\prime}$ & $125.0, \mathrm{CH}$ & $5.97, \mathrm{~d}(2.0)$ & $118.7, \mathrm{CH}$ & $6.48, \mathrm{~d}(2.1)$ \\
\hline $3^{\prime}$ & 199.2, $\mathrm{C}=\mathrm{O}$ & & 200.6, $\mathrm{C}=\mathrm{O}$ & \\
\hline $4^{\prime}$ & $82.8, \mathrm{C}$ & & 79.6, C & \\
\hline $5^{\prime}$ & 77.3, $\mathrm{CH}$ & $4.48, \mathrm{dd}(4.3,1.6)$ & 73.0, $\mathrm{CH}$ & 4.27, dd $(5.9,2.7)$ \\
\hline $6^{\prime}$ & $27.4, \mathrm{CH}_{2}$ & $\begin{array}{c}3.19, \text { dd }(18.8,1.6) \\
2.82, \text { ddd }(18.8,4.3,2.0)\end{array}$ & $32.0, \mathrm{CH}_{2}$ & $\begin{array}{c}3.15 \text {, ddd }(18.5,5.9,2.1) \\
3.08 \text {, dd }(18.5,2.7)\end{array}$ \\
\hline$\alpha$ & $132.3, \mathrm{CH}$ & $7.40, \mathrm{~d}(16.4)$ & $110.7, \mathrm{CH}$ & $7.31, \mathrm{~s}$ \\
\hline$\beta$ & $126.4, \mathrm{CH}$ & 7.01, d (16.4) & 153.2, C & \\
\hline $1^{\prime \prime}$ & $33.0, \mathrm{CH}_{2}$ & $\begin{array}{l}2.54, \mathrm{dd}(14.4,8.0) \\
2.39, \mathrm{dd}(14.4,7.2)\end{array}$ & $35.3, \mathrm{CH}_{2}$ & $\begin{array}{l}2.47, \mathrm{dd}(14.9,7.7) \\
2.40, \mathrm{dd}(14.9,7.0)\end{array}$ \\
\hline $2^{\prime \prime}$ & 118.1, CH & 5.18 , brs & $118.8, \mathrm{CH}$ & 5.22 , brt $(7.3)$ \\
\hline $3^{\prime \prime}$ & $136.0, \mathrm{C}$ & & 135.0, C & \\
\hline $4^{\prime \prime}$ & $26.0, \mathrm{CH}_{3}$ & $1.68, \mathrm{~s}$ & $26.1, \mathrm{CH}_{3}$ & $1.67, \mathrm{~s}$ \\
\hline $5^{\prime \prime}$ & $18.1, \mathrm{CH}_{3}$ & $1.63, \mathrm{~s}$ & $18.1, \mathrm{CH}_{3}$ & $1.58, \mathrm{~s}$ \\
\hline $1^{\prime \prime \prime}$ & $108.0, \mathrm{C}$ & & & \\
\hline $2^{\prime \prime \prime}$ & $27.8, \mathrm{CH}_{3}$ & $1.32, \mathrm{~s}$ & & \\
\hline $3^{\prime \prime \prime}$ & $26.8, \mathrm{CH}_{3}$ & $1.18, \mathrm{~s}$ & & \\
\hline $4-\mathrm{OH}$ & & & & $8.88, \mathrm{~s}$ \\
\hline $4^{\prime}-\mathrm{OH}$ & & & & $4.18, \mathrm{~s}$ \\
\hline $5^{\prime}-\mathrm{OH}$ & & & & $3.83, \mathrm{~s}$ \\
\hline
\end{tabular}

Placement, Induced Fit Refinement, London Dg, and GBVI/ WSA dG scoring methods. Five top poses showed up based on the negative binding free energy value ( $S$ value). The best pose was selected to analyze the receptor-ligand interactions by using BIOVIA Discovery Studio Visualizer 2016 (Dassault Systèmes Americas Corp., Waltham, USA).

\section{Results and Discussion}

3.1. Extraction and Isolation. The dried powdered stems of S. ilicifolius were exhaustively extracted in a Soxhlet extractor with $n$-hexane, EtOAc, and $\mathrm{MeOH}$ to yield the corresponding fractions. The EtOAc-soluble fraction was repeatedly chromatographed using silica gel CC and preparative TLC to obtain two undescribed stilbene derivatives, strebluses C (1) and D (2) (Figure 1).

3.2. Structural Elucidation of Two New Isolated Compounds from S. ilicifolius. Compound 1, streblus C, showed a molecular formula to be $\mathrm{C}_{22} \mathrm{H}_{26} \mathrm{O}_{5}$ based on the HRESIMS sodium adduct ion at $\mathrm{m} / z 393.1704[\mathrm{M}+\mathrm{Na}]^{+}$(calcd for $\mathrm{C}_{22} \mathrm{H}_{26} \mathrm{O}_{5} \mathrm{Na}$, 393.1678). The ${ }^{1} \mathrm{H}$ NMR spectrum showed signals for a 1,2,4-trisubstituted aromatic ring $\left[\delta_{\mathrm{H}} 7.48(\mathrm{~d}\right.$, $J=8.5 \mathrm{~Hz}, \mathrm{H}-6), 6.46(\mathrm{~d}, J=2.4 \mathrm{~Hz}, \mathrm{H}-3), 6.42(\mathrm{dd}, J=8.5$, $2.4 \mathrm{~Hz}, \mathrm{H}-5)$, two trans-coupling olefinic protons $\left[\delta_{\mathrm{H}} 7.40(\mathrm{~d}\right.$, $J=16.4 \mathrm{~Hz}, \mathrm{H}-\alpha), 7.01(\mathrm{~d}, J=16.4 \mathrm{~Hz}, \mathrm{H}-\beta)]$, an $\alpha$-olefinic proton of $\alpha, \beta$-unsaturated carbonyl group $\left[\delta_{\mathrm{H}} 5.97(\mathrm{~d}\right.$, $\left.\left.J=2.0 \mathrm{~Hz}, \mathrm{H}-2^{\prime}\right)\right]$, an oxymethine proton $\left[\delta_{\mathrm{H}} 4.48(\mathrm{dd}\right.$,
$\left.\left.J=4.3,1.6 \mathrm{~Hz}, \mathrm{H}-5^{\prime}\right)\right]$, a prenyl group $\left[\delta_{\mathrm{H}} 2.54(\mathrm{dd}, J=14.4\right.$, $8.0 \mathrm{~Hz}, \mathrm{H}-1^{\prime \prime} \mathrm{a}$ ), 2.39 (dd, J=14.4, 7.2 Hz, H-1"b), 5.18 (brs, $\left.\mathrm{H}-2^{\prime \prime}\right), 1.68\left(\mathrm{~s}, \mathrm{H}_{3}-4^{\prime \prime}\right), 1.63\left(\mathrm{~s}, \mathrm{H}_{3}-5^{\prime \prime}\right)$ ], two methyl groups $\left[\delta_{\mathrm{H}} 1.32\left(\mathrm{~s}, \mathrm{H}_{3}-2^{\prime \prime \prime}\right), 1.18\left(\mathrm{~s}, \mathrm{H}_{3}-3^{\prime \prime \prime}\right)\right]$, and a methylene group $\left[\delta_{\mathrm{H}} 3.19\left(\mathrm{dd}, J=18.8,1.6 \mathrm{~Hz}, \mathrm{H}_{2}-6^{\prime} \mathrm{a}\right), 2.82\right.$ (ddd, $J=18.8,4.3$, 2.0 Hz, $\left.\left.\mathrm{H}_{2}-6^{\prime} \mathrm{b}\right)\right]$. The ${ }^{13} \mathrm{C}$ NMR data (Table 1) exhibited resonances for a keto-carbonyl $\left(\delta_{\mathrm{C}}\right.$ 199.2), six aromatic carbons and six olefinic carbons $\left[\delta_{\mathrm{C}} 103.6-160.8\right]$, an acetonide group $\left[\delta_{\mathrm{C}} 108.0,27.8,26.8\right]$, two oxygenated carbons $\left[\delta_{\mathrm{C}} 82.8,77.3\right]$, two methylene carbons $\left[\delta_{\mathrm{C}} 33.0,27.4\right]$, and two methyl carbons $\left[\delta_{\mathrm{C}} 26.0,18.1\right]$. The HMBC correlations (Figure 2) from $\mathrm{H}-3$ to $\mathrm{C}-1, \mathrm{C}-2$, and $\mathrm{C}-4$, from $\mathrm{H}-5$ to $\mathrm{C}-1$ and C-4, from $\mathrm{H}-6$ to $\mathrm{C}-2$ and C-4, from $\mathrm{H}-\alpha$ to $\mathrm{C}-2$ and C-6, and from $\mathrm{H}-\beta$ to $\mathrm{C}-1$, indicated that two hydroxy groups and $\mathrm{C} \alpha-\mathrm{C} \beta$ double bond located at C-2, C-4, and C-1, respectively, of the 1,2,4-trisubstituted aromatic ring. The presence of the cyclohex-2-en-1-one 5,6-acetonide moiety in 1 was established based on the observed HMBC correlations. The $\mathrm{HMBC}$ correlations from $\mathrm{H}-\alpha$ to $\mathrm{C}-1^{\prime}$ and from $\mathrm{H}-\beta$ to $\mathrm{C}-1^{\prime}$ and $\mathrm{C}-2^{\prime}$ were supportive of the $\mathrm{C} \beta-\mathrm{C} 1^{\prime}$ linkage. In addition, the prenyl group was determined to be located at $\mathrm{C}-4^{\prime}$ by the HMBC correlations from $\mathrm{H}-1^{\prime \prime}$ to $\mathrm{C}=\mathrm{O}, \mathrm{C}-4^{\prime}$, and $\mathrm{C}-5^{\prime}$ and from $\mathrm{H}-5^{\prime}$ to $\mathrm{C}-1^{\prime \prime}$. Therefore, 1 was suggested to be a prenylated stilbene-like compound. The difference in chemical shifts of the methyl groups of the dimethylacetonide moiety in $\mathbf{1}$ is $0.14 \mathrm{ppm}$, which established the presence of the cis-acetonide [13]. Moreover, it was unambiguously confirmed based on the NOESY correlation between $\mathrm{H}-5^{\prime}$ and $\mathrm{H}_{2}-\mathrm{I}^{\prime \prime}$ (Figure 2). The preferred 
<smiles>CC(C)=CCC1(OC(C)(C)C)C(=O)C=C(C=Cc2ccc(O)cc2O)CC1=O</smiles>

(a)<smiles>CC(C)=CC[C@]1(O)C(=O)C=C(c2cc3ccc(O)cc3o2)C[C@H]1O</smiles>

(b)

FIgURE 1: Structure of compounds 1 and 2.

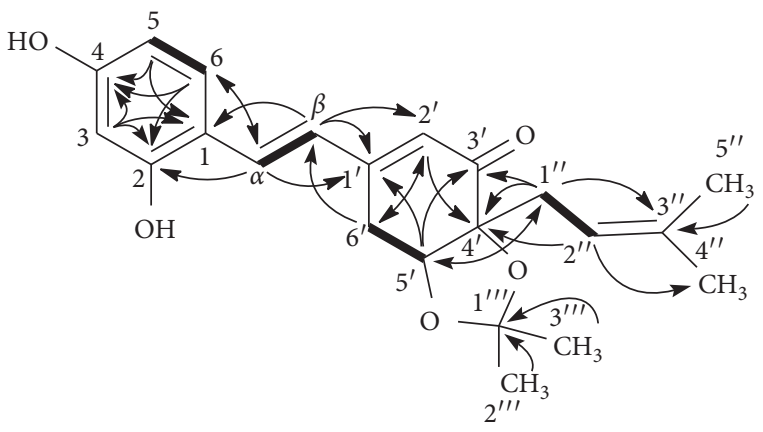

1

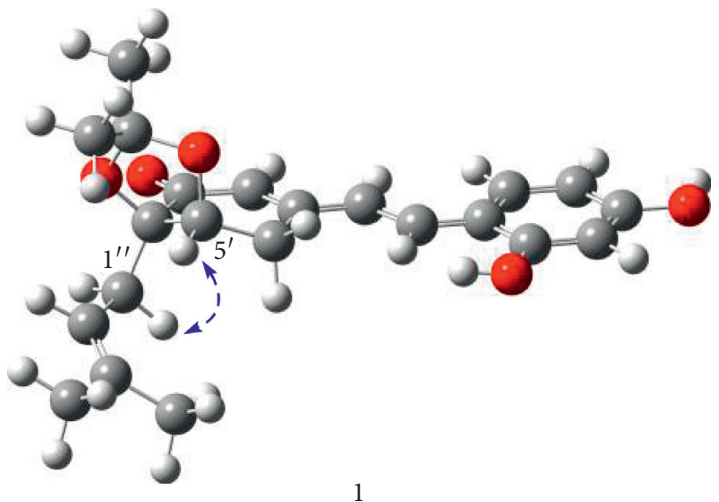

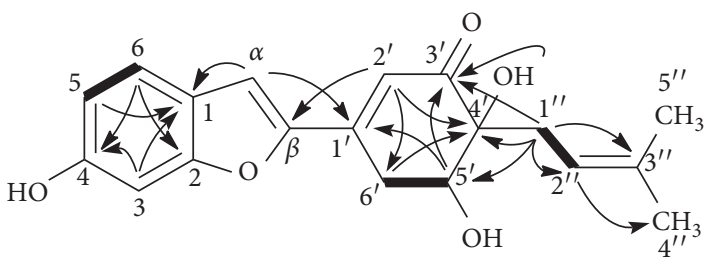

2

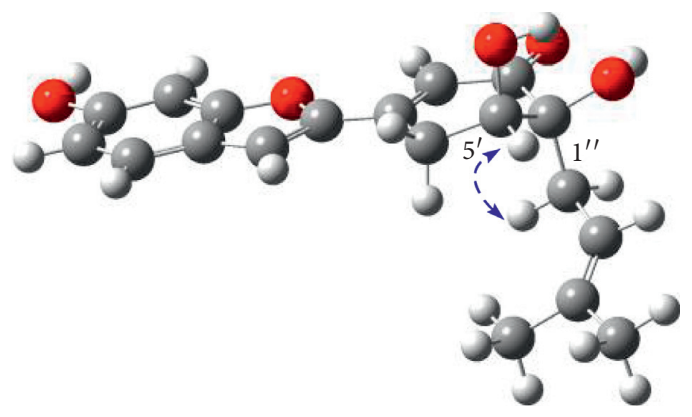

2

FIgUre 2: Significant HMBC (solid arrows) and NOESY (blue, dashed arrows) correlations observed for 1 and 2.

conformations of the cis- $(R, R)$-acetonide $\mathbf{1}$ were generated by the MM2 calculation using MMFF94 force field [14]. These conformers were reoptimized by DFT-B3LYP method using basis set $6-31 \mathrm{G} *$, to obtain the most preferred conformer with $92.8 \%$ Boltzmann distribution (Table S1). The optical rotation value at sodium D line frequency was computed using B3LYP/6-311++G(2d, 2p) level with IEFPCM solvent model for methanol. The large basis set with diffuse functions such as $6-311++G(2 d, 2 p)$ was applied to give very consistent results $[15,16]$. The calculated $[\alpha]_{\mathrm{D}}$ value of $(R, R)$-acetonide 1 was -102.36 , compared with its experimental value $[\alpha]_{\mathrm{D}}:-101.7(c 0.023$, $\mathrm{MeOH})$. Thus, a $(R, R)$ absolute configuration was concluded for streblus C (1).
A careful HPLC analysis of the EtOAc-soluble fraction was accomplished, which revealed a peak at $t_{R} 20.766 \mathrm{~min}$ in the chromatogram in accord with that of $\mathbf{1}\left(t_{R} 20.800 \mathrm{~min}\right)$ (Figure S1). Thus, the presence of $\mathbf{1}$ in the EtOAc-soluble fraction from S. ilicifolius was confirmed, and the possibility of $\mathbf{1}$ being artifact could be ignored.

Compound 2, streblus D, showed a molecular formula to be $\mathrm{C}_{19} \mathrm{H}_{20} \mathrm{O}_{5}$ based on the HRESIMS sodium adduct ion at $\mathrm{m} / z \quad 351.1224[\mathrm{M}+\mathrm{Na}]^{+}$(calcd for $\mathrm{C}_{19} \mathrm{H}_{20} \mathrm{O}_{5} \mathrm{Na}$, 351.1208). The ${ }^{1} \mathrm{H}$ and ${ }^{13} \mathrm{C}$ NMR data of 2 (Table 1) resembled those of $\mathbf{1}$, except for the presence of the singlet olefinic proton at $\delta_{\mathrm{H}} 7.31$ instead of two trans-coupling olefinic protons in $\mathbf{1}$ and disappearance of the acetonide group. Based on the ${ }^{13} \mathrm{C}$ NMR data and observed HMBC 


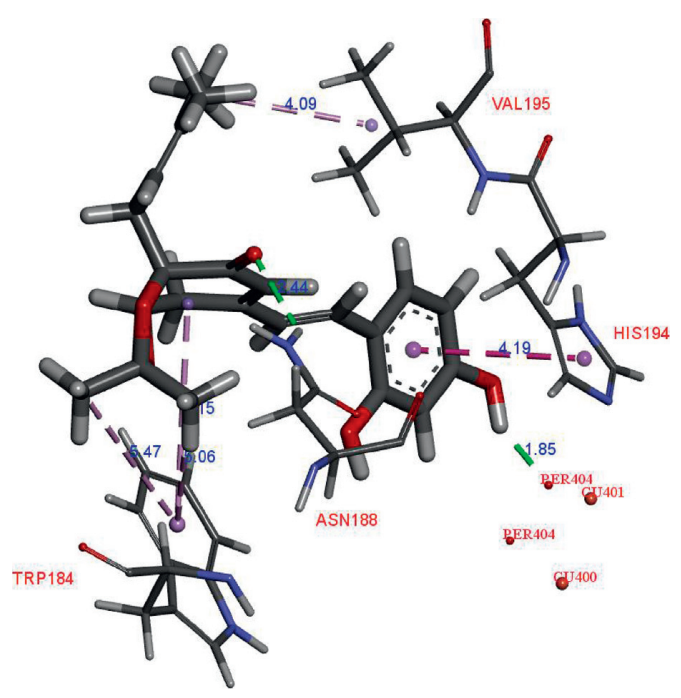

(a)

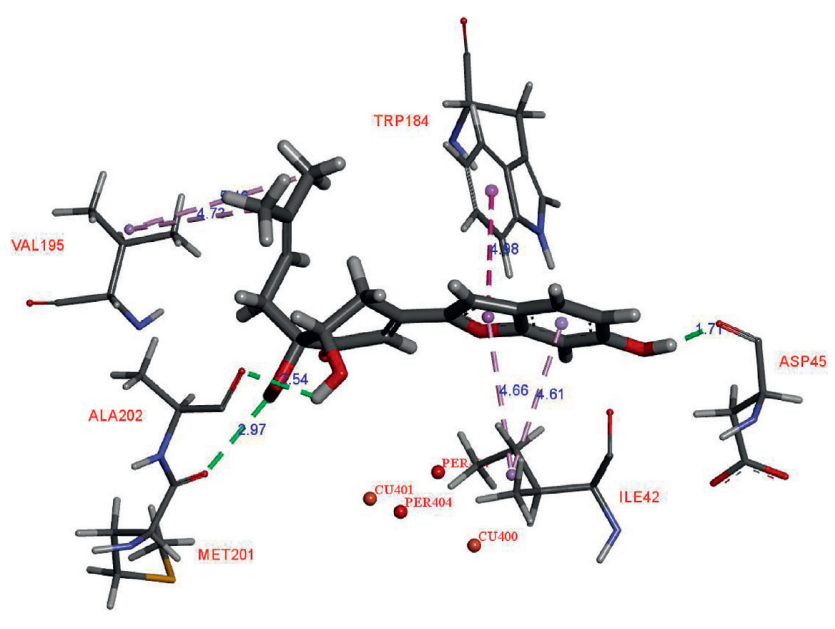

(b)

Figure 3: Docked pose of best ranked docking score of compounds 1 (a) and 2 (b).

correlations for 2 (Figure 2), the structure of 2 was assigned as a benzofuran-type stilbene. The NOESY correlations between $\mathrm{H}-5^{\prime}$ and $\mathrm{H}_{2}-1^{\prime \prime}$ indicated the presence of the cis-diol configuration. The ${ }^{3} J_{\mathrm{H}-5^{\prime} / \mathrm{H}-6^{\prime}}$ coupling constants were 5.9 and $2.7 \mathrm{~Hz}$, to suggest the equatorial configuration of $\mathrm{H}-5^{\prime}$ [17], which was supportive of the $(R, R)$ or $(S, S)$ absolute configurations for 2 . The conformational search for $(R, R)-2$ was generated and optimized to obtain six conformers with total Boltzmann weight $>90 \%$ (Table S1). The Boltzmann-weighted calculated $[\alpha]_{\mathrm{D}}$ value of $(R, R)-2$ was +301.74 , compared with its experimental value $[\alpha]_{\mathrm{D}}$ : -228.9 (c 0.002, $\left.\mathrm{MeOH}\right)$. Thus, a $(S, S)$ absolute configuration was concluded for streblus D (2).

\subsection{Tyrosinase Inhibitory Activity of Isolated Compounds from} S. ilicifolius. Compounds $\mathbf{1}$ and $\mathbf{2}$ were tested for their tyrosinase inhibitory activities [18]. Kojic acid, a purported skin lightening agent, was used as a positive control. Streblus C (1) exhibited remarkable inhibitory effect with an $\mathrm{IC}_{50}$ value of $0.01 \mu \mathrm{M}$, which was 4400 times more potent than that of kojic acid $\left(\mathrm{IC}_{50}, 44.6 \mu \mathrm{M}\right)$. Meanwhile, streblus D (2) was inactive with an $\mathrm{IC}_{50}$ value $>100 \mu \mathrm{M}$. These results were consistent with a previous report on the structure-activity relationships of stilbene derivatives. Compound $\mathbf{1}$ having 2,4-resorcinol subunit contributed the most to inhibitory activity [19]. In addition, the 2-arylbenzofuran derivatives showed lower tyrosinase inhibitory activities than the corresponding stilbene derivatives, suggesting that the formation of the five-membered ring led to the loss of inhibitory activity [20].

3.4. Docking Studies of Compounds $\mathbf{1}$ and 2. Tyrosinase is an oxidase, which is represented as one of four possible forms (deoxy-, oxy-, met-, and deact- forms) [21]. Oxytyrosinase form oxidizes both phenols and catechols to $o$-quinones. Herein, mushroom tyrosinase (EC 1.14.18.1) plays the same role with respect to $o x y$-tyrosinase form. Two bound $\mathrm{Cu}^{2+}$ ions bind to six histidine residues, and the peroxide group is in the binding site of oxy-tyrosinase, which has a role in the catalytic oxidation [22]. To explore the strong inhibitory activity of $\mathbf{1}$ against tyrosinase, the molecular docking studies of $\mathbf{1}$ and 2, respectively, with oxy-tyrosinase (PDB ID:1WX2) were carried out [23].

The docking studies were performed with MOE. The topranked pose with the highest negative binding free energy value ( $S$ value) was selected for further interaction analysis with Discovery Studio Visualizer. Following our previous in silico study on tyrosinase inhibition, this docking procedure was already validated based on the docking results of the positive control (kojic acid) and the decoy (hypoxanthine) [12].

In the binding site, compound $\mathbf{1}$ showed the $\mathrm{H}$-donor interaction between the $\mathrm{C}-4$ hydroxy group and peroxide bridge PER404, presenting the distances of $1.85 \AA$. The $\mathrm{C}-3^{\prime}$ carbonyl group formed the $\mathrm{H}$-acceptor interaction with ASN188 residue (Figure 3 ). The aromatic ring exhibited the $\pi-\pi$ stacking interaction with HIS194 residue localized in the active pocket. In addition, two methyls of the acetonide group showed the $\pi$ - $\sigma$ interactions with TRP184 residue. Compound 2 did not show any interaction with the catalytic site (i.e., $\mathrm{Cu}^{2+}$ ions and peroxide bridge), whereas kojic acid showed the interactions with a $\mathrm{Cu}^{2+}$ ion, HIS194, and THR203 residues in the binding site. Three hydroxy groups of 2 interacted with ASP45, ALA202, and MET201 residues via the $\mathrm{H}$-donor bonding. The furan ring formed the $\pi-\pi$ and $\pi-\sigma$ interactions with TRP184 and ILE42 residues, respectively. The $S$ values and these interactions suggested that $\mathbf{1}$ showed high binding affinity for $o x y$-tyrosinase than that of 2 (Table 2). This result confirmed that the formation of furan ring in $\mathbf{2}$ led to the loss of inhibitory activity. 
TABLE 2: Docking results of $\mathbf{1}$ and $\mathbf{2}$ with $o x y$-tyrosinase.

\begin{tabular}{|c|c|c|c|c|}
\hline \multirow[b]{2}{*}{ Compound } & \multicolumn{4}{|c|}{$o x y$-tyrosinase (1 WX2) } \\
\hline & $\begin{array}{c}S \\
\text { values }\end{array}$ & Interactions & $\begin{array}{l}\text { Targeting } \\
\text { residues }\end{array}$ & $\begin{array}{c}\text { Distance } \\
(\AA)\end{array}$ \\
\hline \multirow{7}{*}{1} & -6.56 & H-donor & PER404 & 1.85 \\
\hline & & H-acceptor & ASN188 & 2.44 \\
\hline & & $\pi-\pi$ & HIS194 & 4.19 \\
\hline & & $\pi-\sigma$ & TRP184 & 5.15 \\
\hline & & & & 5.06 \\
\hline & & & & 5.47 \\
\hline & & $\sigma-\sigma$ & VAL195 & 4.09 \\
\hline \multirow{7}{*}{2} & -6.17 & H-donor & ASP45 & 1.71 \\
\hline & & & ALA202 & 2.54 \\
\hline & & & MET201 & 2.97 \\
\hline & & $\pi-\pi$ & TRP184 & 4.98 \\
\hline & & $\pi-\sigma$ & ILE42 & 4.66 \\
\hline & & & & 4.61 \\
\hline & & $\sigma-\sigma$ & VAL195 & 4.73 \\
\hline \multirow{3}{*}{ Kojic acid ${ }^{\mathrm{a}}$} & -4.50 & H-donor & THR203 & 2.04 \\
\hline & & $\begin{array}{l}\text { Metal- } \\
\text { acceptor }\end{array}$ & CU401 & 2.92 \\
\hline & & $\pi-\pi$ & HIS194 & 4.30 \\
\hline
\end{tabular}

${ }^{\mathrm{a} P o s i t i v e ~ c o n t r o l . ~}$

\section{Conclusions}

Two new stilbene derivatives were isolated from the stems of S. ilicifolius. Their structures were elucidated based on the NMR spectroscopic interpretation and optical rotation calculation. Compound $\mathbf{1}$ was found to possess strong tyrosinase inhibitory activity with an $\mathrm{IC}_{50}$ value of $0.01 \mu \mathrm{M}$. Binding interaction analyses between the isolated compounds ( 1 and 2) and $o x y$-tyrosinase active site have been performed.

\section{Data Availability}

The NMR data used to support the findings of this study are included within the supplementary information file.

\section{Conflicts of Interest}

The authors declare that there are no conflicts of interest regarding the publication of this paper.

\section{Acknowledgments}

This research was funded by Vietnam National University Ho Chi Minh City (VNU-HCM) under grant number NCM2020-18-01.

\section{Supplementary Materials}

Figure S1: HPLC chromatogram of $\mathbf{1}$ from the stems of S. ilicifolius. Table S1: conformational data. Figures S2-S15: copies of spectroscopic data for 1 and 2. (Supplementary Materials)

\section{References}

[1] J. N. Rodríguez-López, J. Tudela, R. Varón, F. García-Carmona, and F. García-Cánovas, "Analysis of a kinetic model for melanin biosynthesis pathway," Journal of Biological Chemistry, vol. 267, no. 6, pp. 3801-3810, 1992.

[2] H. Decker and F. Tuczek, "Tyrosinase/catecholoxidase activity of hemocyanins: structural basis and molecular mechanism," Trends in Biochemical Sciences, vol. 25, no. 8, pp. 392-397, 2000.

[3] T. Pillaiyar, M. Manickam, and V. Namasivayam, "Skin whitening agents: medicinal chemistry perspective of tyrosinase inhibitors," Journal of Enzyme Inhibition and Medicinal Chemistry, vol. 32, no. 1, pp. 403-425, 2017.

[4] S. Dej-adisai, K. Parndaeng, and C. Wattanapiromsakul, "Determination of phytochemical compounds, and tyrosinase inhibitory and antimicrobial activities of bioactive compounds from Streblus ilicifolius (S Vidal) Corner," Tropical Journal of Pharmaceutical Research, vol. 15, no. 3, pp. 497506, 2016.

[5] G. Zhang, L. Hao, D. Zhou et al., "A new phenylpropanoid glycoside from the bark of Streblus ilicifolius (Vidal) Corner," Biochemical Systematics and Ecology, vol. 87, Article ID 103962, 2019.

[6] Y. Huang, X. Huang, G. Tian et al., "Two new amide glycosides with anti-inflammatory activity from the leaves of Streblus ilicifolius (Vidal) corner," Natural Product Research, pp. 1-9, 2021.

[7] N. T. Nguyen, H. X. Nguyen, T. H. Le et al., "Two new derivatives of 8-prenyl-5,7-dihydroxycoumarin from the stems of Streblus ilicifolius (S.Vidal) Corn," Natural Product Research, pp. 1-6, 2021.

[8] N. T. Nguyen, M. H. K. Nguyen, H. X. Nguyen, N. K. N. Bui, and M. T. T. Nguyen, "Tyrosinase inhibitors from the wood of Artocarpus heterophyllus," Journal of Natural Products, vol. 75, no. 11, pp. 1951-1955, 2012.

[9] H. X. Nguyen, N. T. Nguyen, M. H. K. Nguyen et al., “Tyrosinase inhibitory activity of flavonoids from Artocarpus heterophyllous," Chemistry Central Journal, vol. 10, no. 1, p. 2, 2016.

[10] P. H. Dang, T. T. Nguyen, T. H. Le, H. X. Nguyen, M. T. T. Nguyen, and N. T. Nguyen, "A new bischromanone from the stems of Semecarpus caudata," Natural Product Research, vol. 32, no. 15, pp. 1745-1750, 2018.

[11] P. H. Dang, L. T. T. Nguyen, H. T. T. Nguyen et al., "A new dimeric alkylresorcinol from the stem barks of Swintonia floribunda (Anacardiaceae)," Natural Product Research, vol. 33, no. 20, pp. 2883-2889, 2019.

[12] P. H. Dang, T. H. Le, T. N. V. Do, H. X. Nguyen, M. T. T. Nguyen, and N. T. Nguyen, "Diarylalkanoids as potent tyrosinase inhibitors from the stems of Semecarpus caudata," Evidence-Based Complementary and Alternative Medicine, vol. 2021, Article ID 8872920, 8 pages, 2021.

[13] L. C. Dias, T. Augusto, C. C. Perez, and L. J. Steil, "Addition of chiral and achiral allyltrichlorostannanes to chiral \pm -alkoxy aldehydes," Journal of the Brazilian Chemical Society, vol. 20, no. 4, pp. 802-812, 2009.

[14] T. Lewis-Atwell, P. A. Townsend, and M. N. Grayson, "Comparisons of different force fields in conformational analysis and searching of organic molecules: a review," Tetrahedron, vol. 79, Article ID 131865, 2021.

[15] P. J. Stephens, F. J. Devlin, J. R. Cheeseman, and M. J. Frisch, "Calculation of optical rotation using density functional 
theory," The Journal of Physical Chemistry A, vol. 105, no. 22, pp. 5356-5371, 2001.

[16] T. Aharon and M. Caricato, "Compact basis sets for optical rotation calculations," Journal of Chemical Theory and Computation, vol. 16, no. 7, pp. 4408-4415, 2020.

[17] Z. Lin, T. Zhu, Y. Fang, Q. Gu, and W. Zhu, "Polyketides from Penicillium sp. JP-1, an endophytic fungus associated with the mangrove plant Aegiceras corniculatum," Phytochemistry, vol. 69, no. 5, pp. 1273-1278, 2008.

[18] E. T. Arung, I. W. Kusuma, Y. M. Iskandar, S. Yasutake, K. Shimizu, and R. Kondo, "Screening of Indonesian plants for tyrosinase inhibitory activity," Journal of Wood Science, vol. 51, no. 5, pp. 520-525, 2005.

[19] S. Khatib, O. Nerya, R. Musa, M. Shmuel, S. Tamir, and J. Vaya, "Chalcones as potent tyrosinase inhibitors: the importance of a 2,4-substituted resorcinol moiety," Bioorganic \& Medicinal Chemistry, vol. 13, no. 2, pp. 433-441, 2005.

[20] Z.-P. Zheng, K.-W. Cheng, Q. Zhu, X.-C. Wang, Z.-X. Lin, and M. Wang, "Tyrosinase inhibitory constituents from the roots of morus nigra: a structure-activity relationship study," Journal of Agricultural and Food Chemistry, vol. 58, no. 9, pp. 5368-5373, 2010.

[21] C. A. Ramsden and P. A. Riley, "Tyrosinase: the four oxidation states of the active site and their relevance to enzymatic activation, oxidation and inactivation," Bioorganic \& Medicinal Chemistry, vol. 22, no. 8, pp. 2388-2395, 2014.

[22] M. Kanteev, M. Goldfeder, and A. Fishman, "Structurefunction correlations in tyrosinases," Protein Science, vol. 24, no. 9, pp. 1360-1369, 2015.

[23] Y. Matoba, T. Kumagai, A. Yamamoto, H. Yoshitsu, and M. Sugiyama, "Crystallographic evidence that the dinuclear copper center of tyrosinase is flexible during catalysis," Journal of Biological Chemistry, vol. 281, no. 13, pp. 89818990, 2006. 